\title{
Triplex Doppler evaluation of the testes in dogs of different sizes $^{1}$
}

\author{
Mírley B. Souza ${ }^{2 *}$, Antônio C. Mota Filho² ${ }^{2}$ Carmen V.S. Sousa² ${ }^{2}$ Cynthia L.B. Monteiro², \\ Gabriela G. Carvalho' ${ }^{2}$, José N. Pinto ${ }^{2}$, Jussiara C.S. Linhares ${ }^{3}$ and Lúcia D.M. Silva ${ }^{2}$
}

\begin{abstract}
Souza M.B., Mota Filho A.C., Sousa C.V.S., Monteiro C.L.B., Carvalho G.G., Pinto J.N., Linhares J.C.S. \& Silva L.D.M. 2014. Triplex Doppler evaluation of the testes in dogs of different sizes. Pesquisa Veterinária Brasileira 34(11):1135-1140. Laboratório de Reprodução de Carnívoros, Universidade Estadual do Ceará, Campus do Itaperi, Av. Doutor Silas Munguba 1700, Itaperi, Fortaleza, CE 60714-903, Brazil. E-mail: mirley.souza@gmail.com

This study aimed to assess whether there are differences in Doppler velocimetry parameters between different sizes. Twenty dogs were equally divided into small and large groups used in this study. The dogs were evaluated using Triplex ultrasound. Testicular artery was located by Colour Doppler in the spermatic cord, marginal to the testes and intratesticular segments and then, spectral Doppler were used to calculate: peak systolic velocity (PSV), end diastolic velocity (EDV), resistance index (RI) and pulsatility index (PI). The mean testicular volume in the left side was significantly higher than the right side, in both groups. Doppler examination showed higher velocities (EDV) at spermatic cord in large dogs; marginal to the testes was observed higher velocities in small dogs; intratesticular region no differences were observed $(\mathrm{P}<0.05)$ and within the groups differences between segments of the artery were also observed for each parameter. The results showed that there are differences in Doppler velocimetry parameters between different sizes.
\end{abstract}

INDEX TERMS: Testes, ultrasonography, Doppler, canine reproduction.

RESUMO.- [Avaliação Triplex Doppler dos testículos de cães de tamanhos diferentes.] Este trabalho teve como objetivo verificar se existem diferenças nos parâmetros dopplervelocimétricos entre cães de diferentes portes. Para tanto, foram utilizados 20 cães, sendo 10 cães de pequeno porte e 10 cães de grande porte. Foram avaliados pelo Triplex Doppler para localização da artéria testicular nos segmentos de cordão espermático, marginal ao testículo e intratesticular. Após isso, o Doppler espectral foi acionado para cálculo dos parâmetros de velocidade de pico sistólico (VPS), velocidade diastólica final (VDF) e índices de resistência (IR) e pulsatilidade (IP). 0 volume testicular médio do testículo esquerdo foi significativamente maior que o direito em ambos os grupos. Ao Doppler, foram observadas diferenças dos valores entre os portes, sendo as velo-

\footnotetext{
${ }^{1}$ Received on May 22, 2014.

Accepted for publication on November 3, 2014.

${ }^{2}$ Laboratório de Reprodução de Carnívoros, Universidade Estadual do Ceará (UECE), Campus do Itaperi, Av. Doutor Silas Munguba 1700, Itaperi, Fortaleza, CE 60714-903, Brazil. *Corresponding author: mirley.souza@ gmail.com

${ }^{3}$ Departamento de Biologia, Centro de Ciências, Universidade Federal do Ceará, Cx. Postal 6021, Fortaleza, CE 60440-970.
}

cidades no cordão espermático superiores nos animais de grande porte $(\mathrm{P}<0,05)$ e dentro dos grupos também foram observadas diferenças entre as regiões da artéria testicular. Diante do exposto, conclui-se que existem diferenças nos parâmetros dopplervelocimétricos quando comparados animais de diferentes portes, além disso, os parâmetros dopplervelocimétricos são diferentes dependendo da região em que são mensurados.

TERMOS DE INDEXAÇÃO: Testículos, ultrassonografia, Doppler, reprodução canina.

\section{INTRODUCTION}

The ultrasonographic evaluation of the testes allows the study of anatomy, parenchyma and adjacent structures, which is important to detect anatomical abnormalities, as well as guiding interventional procedures for diagnosis purposes (Nyland \& Matton 2004). Two-dimensional ultrasound of the testes enables the assessment of echogenicity and echotexture, besides the measure of testicular volume, which may represent normal development of testes, serving as a tool in detecting testicular diseases (Dogra et al. 2003). 
Triplex Doppler Ultrasound involves the simultaneous use of two-dimensional ultrasound, color Doppler and pulsed Doppler, which allows the gathering of anatomical data of the vessels and functional data regarding blood flow, including its presence or absence, direction and speed, and is the method of choice for assessing the vascularity of various organs, including the testes (Nyland \& Matton 2004, Pozor \& McDonnell 2004, Wood et al. 2010, Souza et al. 2014).

The use of Doppler in Human Medicine for the evaluation of testicular perfusion is already well established (Middleton et al. 1989, Dubinsky et al. 1998). In humans, it is used mainly for the diagnosis of diseases, including testicular torsion and varicocele (Schurich et al. 2009) and also to assist in the diagnosis of obstructive and nonobstructive azoospermia, which may reflect infertility problems (Foresta et al. 1998).

In veterinary medicine, studies using testicular Doppler ultrasound have been performed in stallions (Pozor \& McDonnell 2004), llamas and alpacas (Kutzler et al. 2011) and dogs (Günzel-Apel et al. 2001, Gumbsch et al. 2002, Carrillo et al. 2011, Zelli et al. 2013). In dogs, studies show the course of the testicular artery through the pampiniform plexus, marginally following the testes (Günzel Apel et al. 2001, Gumbsch et al. 2002) using only adult animals in heterogeneous groups, and the intratesticular arteries (Carrillo et al. 2011). However, in order to establish appropriate ultrasonographic parameters is important to determinate possible differences according to size of the animal, establishing normal parameters for the species within specific sizes.

Due to the scarcity of studies on this subject the aim of this study was to compare Doppler velocimetry parameters of testicular artery measured in different regions of the testicular artery, and to compare these parameters between small and large dogs.

\section{MATERIALS AND METHODS}

\section{Experimental animals}

This study was performed in the Laboratory of Carnivore Reproduction of the School of Veterinary Medicine, State University of Ceará (Universidade Estadual do Ceará - UECE / 03 43'02" S / 38 $32^{\prime} 35^{\prime \prime}$ W) and approved by the Animal Ethics Committee of the institution (Protocol no. 12641034-8).

The study included 10 small dogs, with ages ranging from 3 to 6 years, weighing 10 to $13 \mathrm{Kg}$ of French Bulldog breed and 10 large dogs, with ages ranging from 2 to 8 years, weighing 33 to $42 \mathrm{Kg}$ of the Labrador (2), Rottweiler (4) and German Sheppard (4) breeds, belonging to Grande Canafístula kennel, $4^{\circ} \mathrm{Cia}$ de Choque/ CPCÃES kennel and private owners, located in the metropolitan area of Fortaleza in the state of Ceará.

The dogs were kept in individual kennels and fed at maintenance levels with a commercial dry food for dogs and drank water ad libitum. The evaluations were performed in the morning, beginning at 8 a.m and not exceeding 10 a.m.

\section{Breeding soundness evaluation}

Breeding soundness evaluation was initiated with the history of animals. After this, the dogs were subjected to a general clinical examination, performing an inspection of the mucosae and lymph nodes and abdominal palpation, evaluation of their reproductive history and then performing an inspection and palpation of the external organs to assess the presence, the size, the consistency, symmetry and mobility, in addition to their compatibility with body development and age of the animal (CBRA 1998, Cunha 2008). In addition to blood sampling for a complete blood count to certify their health. Only the healthy dogs were used and selected those animals with minimum seminal standard for breeding (Johnston et al. 2001).

To assess the semen quality, each dog was subjected to 3 semen collections, which were performed using the digital manipulation method (Cunha 2008) with 7-day intervals between each collection and only the second fraction was collected. The second fraction was assessed immediately after the collection with respect to the color (from clear to opaque white) and volume (mL) as well as the microscopic parameters of total motility (\%), vigor (1-5), concentration (number of spermatozoa/mL), morphology (\%) and membrane integrity (hypo-osmotic test - \%). Funcionality of the sperm membrane was evaluated by hypo-osmotic test (HOST), performed immediately after sperm recovery, using distilled water as hypo-osmotic solution. An aliquot of the sample was diluted at a ratio of $10-\mu \mathrm{L}$ to $90-\mu \mathrm{L}$ of distilled water and an aliquot of sperm was placed on a glass slide, covered with coverslip, with 200 cells counted with an aid of an optical microscope ate $400 \mathrm{X}$ magnification. After this period, sperm membrane was considered functional when the sperm cell had a curled tail (Quintela et al. 2010). The total motility and vigor were evaluated subjectively using an optical microscope at 400x magnification. The concentration was assessed using a Neubauer chamber and a $10-\mu \mathrm{L}$ aliquot of semen diluted in $2 \mathrm{~mL}$ of saline with $1 \%$ formalin (Cardoso et al. 2003). The total motility and vigor were evaluated subjectively using an optical microscope at 400x magnification. The concentration was assessed using a Neubauer chamber and a $10-\mu \mathrm{L}$ aliquot of semen diluted in $2 \mathrm{~mL}$ of saline with $1 \%$ formalin (Cardoso et al. 2003). The spermatozoa morphology was evaluated by counting 200 cells per sample evaluated, stained with Rose Bengal, and classifying it as normal or abnormal (Oettlé 1993).

\section{Ultrasonography assessment}

The ultrasound analyses were performed using the SonoAce PICO device (Medison Co., Ltd, Daechi-Dong, Kangnam-ku, Cuseoul, Korea) with a multifrequency linear transducer from 5 to $9 \mathrm{MHz}$, performed by the same observer. The animals were positioned in the supine position, the gel (Fort Sam Brasil ${ }^{\circledR}$ - São Paulo, SP, Brazil) was applied to the animal skin, and the transducer was positioned on the testes. Each animal was subjected to 3 ultrasound evaluations with 1-week intervals between each evaluation, and all the assessments were performed immediately after semen collection.

\section{B mode}

First, the B mode ultrasound was performed, evaluating the parameters of echogenicity, echotexture and testicular volume. For this purpose, 2 cuts were made, one in the longitudinal plane (using the mediastinum as a reference point for measuring the testicular length and width) and the other in the transverse plane to assess the height, and the testicular volume was then automatically calculated by the device using these measures. The formula used was the ellipsoid: length (C) X width (W) X thickness (T) X 0.5236 (Paltiel et al. 2002).

\section{Doppler ultrasound}

Scans using B mode color Doppler ultrasound were initially performed to visualize the testicular artery in the region of the spermatic cord, and the procedure was repeated to visualize the testicular artery in the marginal and intratesticular regions of the 
right and left testes for the Doppler velocimetry evaluation of the testicular artery (Souza et al. 2014).

After locating the testicular artery, the evaluation was performed using pulsed Doppler, and the caliper was positioned in the lumen of the vessel, assessing the graphical representation, as a waveform, of the arterial blood flow. The 3 best waves of a cardiac cycle were measured to evaluate the following Doppler velocimetry parameters: peak systolic velocity (PSV), end diastolic velocity (EDV), resistance index (RI) and pulsatility index (PI). The sample size was $2 \mathrm{~mm}$. The angle of insonation used (under $60^{\circ}$ ) and the same operator performed each examination. The color gain was adjusted to reduce the excess of color noise to observe slower blood flows.

\section{Statistical analysis}

The data were tested for normality (Shapiro-Wilk test) and homoscedasticity (Levene test). The values regarding the testicular volume showed a normal distribution and homoscedasticity; thus, an analysis of variance (ANOVA) of repeated measures was performed for the comparisons between weeks in each group evaluated, and the paired t test was used for the comparisons between the right and left testes. The t test was performed to assess the possible differences between the groups.

The comparison of the Doppler velocimetry parameters of the testicular artery between weeks was performed by an analysis of variance (ANOVA) of repeated measures when data showed normal distribution, and Friedman test when data didn't attend the assunptions of parametric statistic. The test was performed to compare Doppler velocimetry parameters between right and left testes. The comparison of these parameters between different regions didn't show homoscedasticity and was performed using the Friedman test. In order to verify differences between dogs of different sizes $t$ test was performed when data showed a normal distribution and U test when they didn't. A significance level of P $<0.05$ was used in all cases, and the results were expressed as the mean \pm standard deviation.

\section{RESULTS}

The clinical, ultrasound and breeding soundness evaluations had an average length of 40 minutes (ranging from 30 minutes to 50 minutes), with no need for sedation at the time of evaluation. The external evaluation of the testes by palpation showed that the testes of all animals studied had a firm consistency, with thin scrotal skin and without abrasions. The fresh semen evaluation showed that all ejaculates were white and had an opaque appearance. In addition, the other macro- and microscopic parameters were normal (Table 1).

The B mode ultrasound showed that the testicular echogenicity of the studied animals was homogeneous in both
Table 1. Mean \pm SD (Standard Deviation) of the seminal parameters of small and large dogs, evaluated using fresh semen $(n=60)$

\begin{tabular}{lcc}
\hline Seminal parameters & Small Dogs & Large Dogs \\
\hline Volume (mL) & $1.20 \pm 0.65$ & $0.94 \pm 0.61$ \\
Total motility (\%) & $96.04 \pm 8.72$ & $95.00 \pm 5.43$ \\
Vigor (0-5) & $4.79 \pm 0.39$ & $4.7 \pm 0.54$ \\
Sperm concentration & $694.00 \pm 530.29$ & $1218.00 \pm 1153.23$
\end{tabular}

(No. spermatozoa X 106/mL)

Hypo-osmotic swelling test (HOST) $\quad 87.61 \pm 7.79 \quad 89.52 \pm 8.98$

Normal spermatozoa (\%) 92.36 $\quad 96.34 \quad 86.72 \pm 11.96$

Table 2. Testicular volume (Mean \pm SD) from right and left sides in small and large dogs

\begin{tabular}{lll}
\hline Testis & Small dogs & Large dogs \\
\hline Right & $4.63 \pm 1.07^{\mathrm{a}}$ & $10.77 \pm 1.66^{\mathrm{a}}$ \\
Left & $4.98 \pm 1.18^{\mathrm{b}}$ & $12.17 \pm 2.22^{\mathrm{b}}$
\end{tabular}

Different lowercase letters represent significant differences in testicular volume between right and left testis $(\mathrm{P}<0.05)$.

groups, with clear visualization of the mediastinum testis as a thin hyperechoic central line when viewed in the longitudinal plane and as a hyperechoic central point when viewed in the transverse plane. The comparison between right and left sides showed that the left testis showed higher values than the right testis (Table 2).

The color Doppler analysis allowed the identification of the testicular artery in all sites studied in the left and right testes. In the spermatic cord region, the artery showed a tortuous pattern along its entire length. Conversely, the artery showed a more linear path marginally to the testicle compared with the spermatic cord, and it was observed along the entire length of the testicle. The intratesticular artery branches were harder to observe but could be seen throughout the testicular parenchyma, with a linear path toward the mediastinum testis.

When visualized by spectral Doppler, the waveform of the testicular artery blood flow was monophasic in the 3 segments, with systolic peaks, decreasing diastolic flow and low vascular resistance. This characteristic could be observed in both small (Figure 1) and large dogs (Figure 2).

The comparison of Doppler velocimetry parameters between sizes, in spermatic cord region, PSV showed no differences between small and large dogs. EDV showed higher values in large dogs, RI and PI parameters were higher in small dogs. In marginal region of the testis PSV and EDV were higher in small dogs and RI and PI parameters didn't show difference between the groups. In the intratesticular

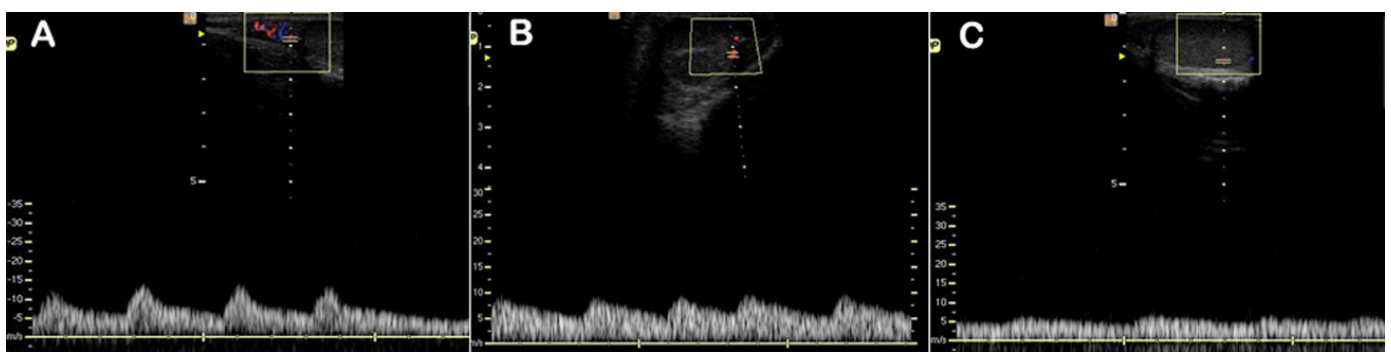

Fig.1. (A) Triplex Doppler of the canine testicular artery viewed in the spermatic cord, (B) marginal to the testicle, and (C) in the intratesticular area in small dogs. 


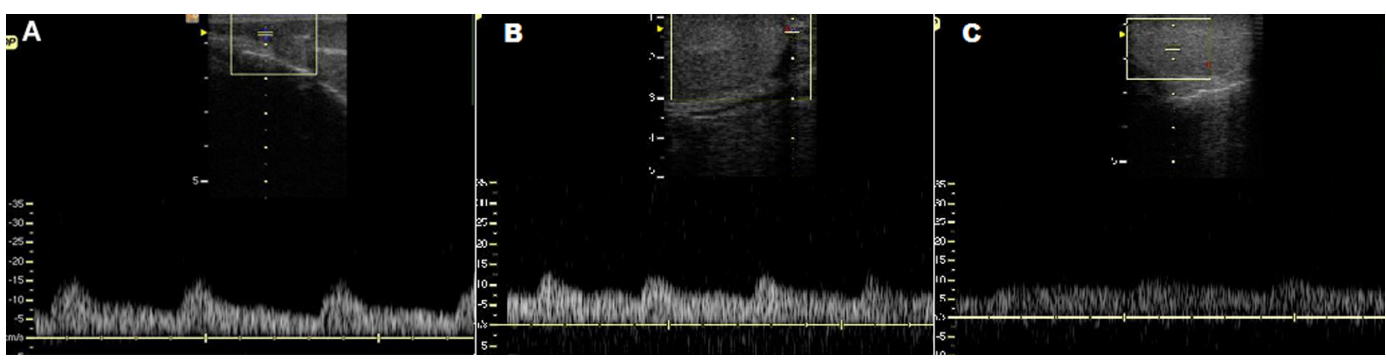

Fig.2. (A) Triplex Doppler of the canine testicular artery viewed in the spermatic cord, (B) marginal to the testicle, and (C) in the intratesticular area in large dogs.

Table 3. Mean \pm SD of the Doppler velocimetry parameters of the testicular arteries of small and large dogs. $1 \mathrm{st}=$ testicular artery located in the spermatic cord, $2 \mathrm{nd}=$ marginal artery and $3 \mathrm{rd}=$ intratesticular artery

\begin{tabular}{|c|c|c|c|c|c|c|}
\hline & \multicolumn{3}{|c|}{ Small dogs } & \multicolumn{3}{|c|}{ Large dogs } \\
\hline & \multicolumn{3}{|c|}{ Region } & \multicolumn{3}{|c|}{ Region } \\
\hline & $1^{\mathrm{a}}$ & $2^{\mathrm{a}}$ & $3^{\mathrm{a}}$ & $1^{\mathrm{a}}$ & $2^{\mathrm{a}}$ & $3^{\underline{a}}$ \\
\hline PSV & $14.20 \pm 2.45^{\underline{a} A}$ & $12.67 \pm 2.27^{\mathrm{bA}}$ & $6.97 \pm 1.20^{\mathrm{cA}}$ & $13.34 \pm 2.59^{\mathrm{aA}}$ & $11.27 \pm 3.04^{\mathrm{bB}}$ & $6.87 \pm 1.15^{\mathrm{cA}}$ \\
\hline EDV & $5.78 \pm 1.56^{\mathrm{aA}}$ & $7.79 \pm 1.60^{\mathrm{bA}}$ & $4.53 \pm 0.95^{\mathrm{cA}}$ & $6.71 \pm 1.77^{\mathrm{aB}}$ & $6.85 \pm 1.81^{\mathrm{aB}}$ & $4.73 \pm 0.88^{\mathrm{bA}}$ \\
\hline RI & $0.59 \pm 0.08^{\mathrm{aA}}$ & $0.39 \pm 0.07^{\mathrm{bA}}$ & $0.35 \pm 0.08^{\mathrm{bA}}$ & $0.49 \pm 0.12^{\mathrm{aB}}$ & $0.38 \pm 0.08^{\mathrm{bA}}$ & $0.32 \pm 0.04^{\mathrm{cB}}$ \\
\hline PI & $0.99 \pm 0.24^{\mathrm{aA}}$ & $0.51 \pm 0.12^{\mathrm{bA}}$ & $0.45 \pm 0.12^{\mathrm{cA}}$ & $0.75 \pm 0.29^{\mathrm{aB}}$ & $0.49 \pm 0.15^{\mathrm{bA}}$ & $0.39 \pm 0.09^{\mathrm{cB}}$ \\
\hline
\end{tabular}

Different lowercase letters represent significant differences in the Doppler velocimetry parameter between regions of the testicle $(\mathrm{P}<0.05)$. Different uppercase letters represent significant differences in the Doppler velocimetry parameter of the respective region between small and large dogs $(\mathrm{P}<0.05)$.

region, PSV and EDV didn't differ between sizes, RI and PI showed superior values in small dogs (Table 3).

Within each group, Doppler velocimetry parameters showed no differences between the evaluation weeks or between the left and right sides, therefore the data were pooled. When only different anatomical region of the testicular artery were evaluated, distinct values for each one of the parameters could be observed. For each group, PSV significantly decreased from spermatic cord to intratesticular region. EDV showed different results between groups, being higher in the spermatic cord region and significantly decreased in the marginal and intratesticular regions, however, large dogs had significantly higher values in marginal region than intratesticular region. RI also showed different behavior between groups, with higher values in spermatic cord region when comparing marginal region in small dogs; in large dogs, RI showed difference between regions, with higher values in spermatic cord region. PI for both groups showed differences between regions, significantly decreasing from spermatic cord to intratesticular region.

\section{DISCUSSION}

The breeding soundness evaluation of the experimental animals showed that the animals were healthy and able to participate in the study. Both groups exhibited characteristics related to the palpation and inspection of the testes and penis, as well as seminal parameters within the normal range for the canine species (CBRA 1998, Johnston et al. 2001).

The ultrasound appearance of the testes in this study was consistent with what has been previously described for dogs (Nyland \& Matton 2004), bulls (Cardilli et al. 2012) and men (Blavias \& Brannam 2004), wherein the testicu- lar parenchyma is described as a structure of homogeneous echogenicity. In both groups, the mediastinum testis may be visualized as a thin central hyperechoic line. These characteristics show that the testes were within normal standard.

The assessment of testicular volume is crucial to determine the reproductive development of the animal and serves as a tool for diagnosing diseases that may lead to testicular function changes because the volume increase may signal infectious or tumor changes in the organ, impairing spermatogenesis, as has been previously reported in humans (Foresta et al. 1998, Shiraishi et al. 2009).

The measurement of testicular volume showed that the left testis is significantly larger than the right one, which was also observed in bulls (Kavac et al. 2003) and dogs (Souza et al. 2012), demonstrating in that specie an assymetry between right and left sides.

The use of color Doppler has become key in the evaluation of testicular vascularization because it enables the description of the vascular structure, the presence or absence of blood flow in the organ and the assessment of the direction and velocity of the blood flow (Rubens et al. 2006).

The use of color Doppler enabled the identification of the testicular artery located in the spermatic cord, marginal to the testicle and in the intratesticular region, as previously reported in dogs (Gumbsch et al. 2002, Carrillo et al. 2011, Souza et al. 2014). All evaluations were able to assess the blood flow in the 3 studied segments, in contrast to the observations of Gumbsch et al. (2002), who reported that the intratesticular artery evaluation could not be performed in $41.5 \%$ of cases. The results found in this study may be explained by the fact that the animals used in the experiment were calm, thereby allowing for the ultrasound assessment of the entire testicular surface. 
The visualization of the testicular artery in the spermatic cord was easier than in the other locations, showing a tortuous pattern that is also observed in humans (Middleton et al. 1989), horses (Pozor \& McDonnell 2004) and dogs (Günzel-Apel et al. 2001, Gumbsch et al. 2002, Carrillo et al. 2011). The marginal artery also showed similar characteristics to the same species reported above. Conversely, in this study, the intratesticular arteries showed a linear pattern directed towards the mediastinum, which is in contrast to that reported by Günzel-Apel et al. (2001), who were not able to visualize or measure the intratesticular flow. In humans, studies have shown that the intratesticular arteries were best viewed in planes oblique to the longitudinal and transversal planes, a finding that is similar to that observed in the present study (Middleton et al. 1989).

The waves obtained in the spectral Doppler were consistent with the waves described by Carvalho et al. (2008), who reported that parenchymal organs such as the testes showed monophasic waves because they need constant perfusion. The waveform characteristics observed in this study have also been observed in humans (Middleton et al. 1989) and dogs (Gumbsch et al. 2002). However, another study in dogs (Carrillo et al. 2011) showed that the waves recorded in the spermatic cord location had biphasic resistant characteristics, similar to those obtained in stallions (Pozor \& McDonnell 2004). This observation is explained by the location of the testicular artery in the spermatic cord being closer to the abdominal aorta, with a flow similar to that of this artery. The measurement at this location should preferably be performed at a single point to avoid different wave patterns.

The wave characteristics were similar between groups in this study, as previously reported in dogs (Gumbsch et al. 2002). These results are consistent with healthy adult animals in reproductive age and capable of fertilization (Zelli et al. 2013).

The comparison of the Doppler velocimetry parameters between groups showed differences in the values, demonstrating that, depending on the region which testicular artery is examined, the parameters are higher in small dogs, differing from Gumbsch et al. (2002) who observed no difference in parameters when correlated with animal's weight. This difference may be explained by the lenght of the testicular artery, which may vary according to weight. Brito et al. (2004), assessing different bulls, determined differences in the lenght of the testicular artery between european (Bos taurus), zebu (Bos indicus) and crossbreed bulls, being longer in the last one, which leads to more blood coming into the spermatic cord region in heavier animals. These findings in bulls suggest the same pattern could be observed in dog, and the larger the size the greater is the lenght of the testicular artery.

The differences observed in Doppler velocity parameters between in regions of the testicular artery, with reduced velocities and increased indexes, may be explained by the artery anatomy. In adults, as soon as the testicular artery emerges from spermatic cord, the artery stretches and extends through epididimal margin of the testes, close to capsule, in a linear pattern and no branches. The artery in marginal region shows thinner walls and a greater inner diameter than in spermatic cord, due to the fact that the testicular artery in spermatic cord region had to stretch more than usual to compensate testicular migration to scrotum (Setchell \& Breed, 2006). This fact causes an increase in the blood flow velocity at spermatic cord region, which decreases as the artery penetrates in other regions of the testes. Another explanation is the thickness of the artery wall and its distance to the lumen of the vessel decreases as it approaches the testes, which may explain the decreasing velocities observed in this study (Brito et al. 2004).

\section{CONCLUSION}

Ultrasonography can be used to characterize the testes of different size dogs. Futhermore, Doppler velocimetry parameters show differences between spermatic cord, marginal and intratesticular regions, with decreasing velocities as it approaches to testicular parenchyma, besides, these parameters differ according to size, with large dogs showing higher velocities in spermatic cord region.

Acknowledgements.- The authors would like to thank the funding agencies, CAPES, CNPq and FUNCAP. The authors also thank São Lázaro Kennel ( $4^{\text {th }}$ Cia de Choque/CPCÃES), Grande Canafístula Kennel and private owners for providing the animals used in this experiment. Finally, the authors would like to thank the veterinarian Herlon Victor Rodrigues Silva for helping on the execution of this study.

\section{REFERENCES}

Blavias M. \& Brannam L. 2004. Testicular ultrasound. Emerg. Med. Clin. North Am. 22:723-748.

Brito L.F.C., Barth A.D., Wilde R.E. \& Kastelic J.P. 2014. Testicular thermoregulation in Bos indicus, crossbred and Bos taurus bulls: relationship with scrotal, testicular vascular cone and testicular morphology, and effects on semen quality and sperm production. Theriogenology 61:511-528.

Cardoso R.S.C., Silva A.R., Uchoa D.C. \& Silva L.D.M. 2003. Cryopreservation of canine semen using a coconut water extender with egg yolk and three different glycerol concentration. Theriogenology 59:743-751.

Cardilli D.J., Toniollo G.H., Pastore A.A., Canola J.C., Oliveira J.A. \& Mercadante M.E.Z. 2012. Ultrassonografia testicular em bovinos jovens da raça Nelore criados em sistema extensivo. Arq. Bras. Med. Vet. Zootec. 64:75-82.

Carrillo J.D., Soler M., Lucas X. \& Agut A. 2011. Colour and Pulsed Doppler ultrasonografic study of the canine testis. Reprod. Dom. Anim. 47:655659.

Carvalho C.F., Chammas M.C. \& Cerri G.G. 2008. Princípios físicos do Doppler em ultrassonografia. Ciência Rural 38:872-879.

CBRA 1998. Manual para Exame Andrológico e Avaliação de Sêmen Animal. Colégio Brasileiro de Reprodução Animal, Belo Horizonte. 52p.

Cunha I.C.N. 2008. Exame andrológico no cão. J. Bras. Ciênc. Anim. 1:49-65.

Dogra V.S., Gottlieb R.H., Oka M. \& Rubens D.J. 2003. Sonography of the scrotum. Radiology 227:18-36.

Dubinsky T.J., Chen P. \& Maklad N. 1998. Color-flow and Power Doppler imaging of the testis. World J. Urol. 16:35-40.

Foresta C., Garolla A., Bertella A., Ferlin A., Rossato M. \& Candiani F. 1998. Doppler ultrasound of the testis in azoospermic subjects as a parameter of testicular function. Hum. Reprod. 13:3090-3093.

Gumbsch P., Holzmann A. \& Gabler C. 2002. Colour-coded duplex sonography of the testes in dogs. Vet. Rec. 151:140-44.

Günzel Apel A.R., Moè Hrke C. \& Poulsen Nautrup C. 2001. Colour-coded and Pulsed Doppler Sonography of the canine testis, epididymis and 
prostate gland: physiological and pathological findings. Reprod. Dom. Anim. 36:236-240.

Johnston S.D., Kustritz M.R.V. \& Olson P.N.S. 2001. Canine and Feline Theriogenology. W.B. Saunders, Philadelphia. 592p.

Kavac A., Lundeheim N., Aidnik M. \& Einarsson S. 2003. Testicular measurements and daily sperm output of Tori and Estonian breed stallions. Reprod. Dom. Anim. 38:167-169.

Kutzler M., Tyson R., Grimes M. \& Timm K. 2011. Determination of testicular blood flow in camelids using vascular casting an color pulsed-wave Doppler ultrasonography. Vet. Med. Int. 1:1-7.

Middleton W.D., Thorne D.A. \& Melson G.L. 1989. Color Doppler ultrasound of the normal testis. Am. J. Roentgenol. 152:293-297.

Nyland T.G. \& Matton J.S. 2004. Prostate and testis, p.255-271. In: Nyland T.G. \& Matton J.S. (Eds), Small Animal Diagnostic Ultrasound. $4^{\text {th }}$ ed. W.B. Saunders. Philadelphia, 461p.

Oettlé E. 1993. Sperm morphology and fertility of the dog. J. Reprod. Fertil. 47(Suppl.):257-260.

Paltiel H.J., Diamond D.A., Di Canzio J., Zurakowski D., Borer J.G. \& Atala A. 2002. Testicular volume: comparison of orchidometerand US measurements in dogs. Radiology 222:114-119.

Pozor M.A. \& McDonnell S.M. 2004. Color Doppler ultrasound evaluation of testicular blood flow in stallions. Theriogenology 61:799-810.

Quintela A.T., Oliveira I.R.S., Souza A.O., Gusmão A.L. \& Silva A.R. 2010.
Water-induced hypo-osmotic test for the evaluation of canine sperm membrane integrity. Anim. Reprod. 7:70-74.

Rubens D.J., Bhatt S., Nedelka S. \& Cullinan J. 2006. Doppler artifacts and pitfalls. Ultrasound Clin. 1:79-109.

Schurich M., Aigner F., Frauscher F. \& Pallwein L. 2009. The role of ultrasound in assessment of male fertility. Eur. J. Obstet. Gynecol. 144:192198.

Setchell B.P. \& Breed W.G. 2006. Anatomy, vaculature and innervations of the male reproduction tract, p.771-825. In: Neill J.D. (Ed.), Knobil's and Neill's Physiology of Reproduction. Elsevier, New York.

Souza M.B., Barbosa C.C., Pinto J.N., Uchoa D.C., Campello C.C. \& Silva L.D.M. 2012. Comparison of testicular volume between French Bulldog and Brazilian Terrier dogs. Proc. International Symposium on Canine and Feline Reproduction, Whistler, Canada. 2p. (Abstracts)

Souza M.B., Barbosa C.C., Pereira B.S., Monteiro C.L.B., Pinto J.N., Linhares J.C.S. \& Silva L.D.M. 2014. Doppler velocimetric parameters of the testicular artery in healthy dogs. Res. Vet. Sci. 96:533-536.

Wood M.M., Romine L.E., Lee Y.K., Richman K.M., O’Boyle M.K., Paz D.A., Chu P.K. \& Pretorius D.H. 2010. Spectral Doppler signatures waveforms in ultrasonography. Ultrasound Q. 26:283-299.

Zelli R., Troisi A., Elad Ngonput A., Cardinali L. \& Polisca A. 2013. Evaluation of testicular artery blood flow by Doppler ultrasonography as a predictor of spermatogenesisin the dog. Res. Vet. Sci. 95:632-637. 